\title{
A Rede Brasileira de Produção Pública de Medicamentos na perspectiva da gestão de cadeias de suprimentos: o papel das TIC
}

Ana Luíza Pimenta de Souza

Fundação Oswaldo Cruz (Fiocruz)

Rio de Janeiro / RJ - Brasil

Claudio Pitassi

Instituto Brasileiro de Mercado de Capitais (IBMEC) / Mestrado em Administração

Rio de Janeiro / RJ - Brasil

Marco Aurélio Carino Bouzada

Universidade Estácio de Sá / Programa de Pós Graduação em Administração

Rio de Janeiro / RJ - Brasil

Antônio Augusto Gonçalves

Universidade Estácio de Sá / Programa de Pós Graduação em Administração

Rio de Janeiro / RJ - Brasil

\begin{abstract}
A indústria farmacêutica configura-se como um oligopólio, com produtos diferenciados em segmentos de classes terapêuticas específicas. As grandes farmacêuticas globais concentram seus esforços de pesquisa e de comercialização nas doenças degenerativas, que trazem maior retorno financeiro. No Brasil, destaca-se a presença de um conjunto de laboratórios públicos, os quais compõem a Rede Brasileira de Produção Pública de Medicamentos (RBPPM), voltados para as necessidades do Sistema Único de Saúde (SUS), em grande parte negligenciadas pelas Big Pharmas. O objetivo deste estudo é investigar o uso pelos laboratórios farmacêuticos oficiais brasileiros das contribuições derivadas das tecnologias da informação e comunicação (TIC), no sentido da integração da cadeia de suprimentos da RBPPM. Em sua primeira fase, a pesquisa de campo foi realizada por meio de uma abordagem quantitativa em todos os laboratórios oficiais afiliados à Associação de Laboratórios Farmacêuticos Oficiais Brasileiros (Alfob). Essa análise permitiu levantar questões que foram aprofundadas por meio da abordagem qualitativa em três laboratórios selecionados da fase anterior. As evidências coletadas permitem concluir que os objetivos descritos na criação da RBPPM, cujo alcance poderia ser facilitado pela adoção dos atributos da GCS pela rede capitaneada pelo Ministério da Saúde, ainda são inci-
\end{abstract}

DOI: http://dx.doi.org/10.1590/0034-7612132157

(cc) BY-NC

Artigo recebido em 18 mar. 2014 e aceito em 5 dez. 2014.

Rev. Adm. Pública - Rio de Janeiro 49(3):615-641, maio/jun. 2015 
pientes e erráticos. O estudo demonstrou que, apesar das evidências teóricas e empíricas a respeito da capacidade das TIC de integrar processos, os laboratórios públicos brasileiros ainda fazem pouco uso das tecnologias estudadas na gestão de cadeias de suprimento (GCS), e o desempenho das poucas ferramentas encontradas revelou-se incipiente e insatisfatório. É bem provável que essa evidência seja uma decorrência natural do fato de que a RBPPM não utilizava uma abordagem de GCS na época em que esta pesquisa foi realizada.

Palavras-chave: tecnologia da informação e comunicação (TIC); cadeia de suprimentos; gestão de cadeias de suprimento (GCS); laboratórios farmacêuticos oficiais brasileiros.

La Red Brasileña de Producción de Medicamentos Pública en la perspectiva de la gestión de la cadena de suministro: el papel de las TIC

La industria farmacéutica se caracteriza por ser un oligopolio con productos diferenciados en segmentos específicos de clases terapéuticas. Las grandes farmacéuticas globales enfocan sus esfuerzos de marketing en las enfermedades degenerativas, que aportan una mayor rentabilidad. En Brasil, existe la presencia de un conjunto de laboratorios públicos, que constituyen la Red Brasileña de Producción Pública de Medicamentos (RBPPM), centrado en las necesidades del Sistema Único de Salud (SUS), en gran parte descuidadas por las grandes empresas farmacéuticas. El objetivo de este estudio es investigar el uso por los laboratorios farmacéuticos oficiales brasileños de las contribuciones derivadas de la tecnología de información y comunicación (TIC), hacia la integración de la cadena de suministro de la RBPPM. En su primera fase, la investigación de campo se llevó a cabo por medio de un enfoque cuantitativo en todos los laboratorios oficiales afiliados a la Asociación Brasileña de Laboratorios Farmacéuticos (Alfob). Este análisis permitió plantear cuestiones que se profundiza con enfoque cualitativo en tres laboratorios seleccionados de la fase anterior. Las pruebas recogidas sugieren que los objetivos descritos en la creación de RBPPM, cuyo alcance podría ser facilitado por la adopción de los atributos GCS pela red liderada por el Ministerio de Salud, es aún pobre y errática. El estudio mostró que a pesar de la evidencia teórica y empírica del potencial de las TIC para integrar los procesos, los laboratorios públicos brasileños todavía hacen poco uso en la gestión de la cadena de suministro de las tecnologías estudiadas y el rendimiento de las pocas herramientas que se encuentran si reveló incipiente e insatisfactoria. Lo más probable es que la evidencia es una consecuencia natural del hecho de que el RBPPM no se utiliza un enfoque de SMC en el momento que se llevó a cabo esta investigación.

Palabras clave: tecnología de la información y la comunicación (TIC); cadenas de suministro; gestión de cadena de suministro (GCS); laboratorios farmacéuticos oficiales brasileños.

The Brazilian Network for Public Production of drugs in the perspective of supply chain management: the role of ICTs

The pharmaceutical industry is characterized as an oligopoly with differentiated products in segments of specific therapeutic classes. The global pharmaceutical companies focus their research and marketing efforts on degenerative diseases, as they bring bigger income as result. In Brazil, a distinctive feature is the presence of a set of public laboratories, which comprise the Brazilian Network of Public Production of Medicines (RBPPM), targeting the needs of the Unified Health System (SUS), in great part ignored by the Big Pharmas. The aim of this study is to investigate the use by Brazilian Official Pharmaceutical Laboratories of contributions derived from the Information and Communication Technologies (ICT), towards the integration of RBPPM's supply chain. In its first phase, the field research was carried out through a quantitative approach in all affiliated Alfob official laboratories. This analysis allowed to raise issues that have been deepened by qualitative approach in three laboratories selected from the previous phase. Collected evidences allowed to conclude that the objectives defined by the Health 
Department at the creation of RBPPM, that could be facilitated by the adoption of the attributes of the SCM network headed, are still incomplete and erratic. The study demonstrated that despite the theoretical and empirical evidences about the capacity of ICT to integrate processes, the Brazilian government labs still make little use of ICT supply chain management (SCM) technologies, and the performance the few tools found proved unsatisfactory and incipient. It is likely that this evidence is a natural consequence of the fact that RBPPM did not use an approach of SCM at the time this research was conducted.

KEYWORDS: information and communication technologies (ICTs); supply chain; supply chain management (SCM); Brazilian official pharmaceutical laboratories.

\section{Introdução}

A indústria farmacêutica tem como atividade principal a produção e a comercialização de medicamentos ou outros produtos voltados para a manutenção e a recuperação da saúde e do bem-estar das pessoas. Dada a característica dos produtos que disponibiliza para a sociedade, é considerada um dos ramos industriais mais relevantes, tanto do ponto de vista econômico quanto social (Mesquita e Santoro, 2004). Também por essa razão, a comercialização dos medicamentos no caso de economias em desenvolvimento, com o perfil sociodemográfico semelhante ao Brasil, enseja complexas questões éticas e de soberania nacional (Magalhães, 2010).

Quanto à estrutura de mercado, a indústria farmacêutica configura-se como um oligopólio, com produtos diferenciados em segmentos de classes terapêuticas específicas. Dados apontam que as 10 maiores empresas farmacêuticas do mundo respondem por cerca de $40 \%$ do mercado mundial e que cerca de 100 companhias de grande porte são responsáveis por aproximadamente $90 \%$ dos produtos farmacêuticos para consumo humano (Françoso e Strachman, 2013; Oliveira, Labra e Bermudez, 2006). Regra geral, as empresas de ponta concentram seus esforços de pesquisa e de comercialização nas doenças degenerativas, tais como câncer e Alzheimer, que geram maiores retornos financeiros (Moreira e Pitassi, 2013).

A dinâmica da indústria é determinada pela inovação tecnológica (Chiaroni, Chiesa e Frattini, 2008; Malerba e Orsenigno, 2002) e, ao nível da firma individual, essa dinâmica depende da capacidade tecnológica acumulada pelas farmacêuticas em cada país (Moreira e Pitassi, 2013). Durante três quartos do século passado, a indústria foi dominada por organizações oriundas da Tríade, ou seja, América do Norte, Europa Ocidental e Japão, as quais ainda detêm $87 \%$ das vendas globais (Françoso e Strachman, 2013).

O Brasil é o oitavo mercado farmacêutico no mundo. Por conseguinte, é uma das nações em desenvolvimento que mais desperta o interesse das farmacêuticas globais (Oliveira, Labra e Bermudez, 2006). Em função do favorecimento dado, ao longo dos governos de Juscelino Kubitschek e dos militares, aos investimentos das grandes transnacionais do setor, o ramo farmacêutico brasileiro foi dominado pelas chamadas Big Pharmas durante boa parte do século passado. Em parte por esse motivo, as farmacêuticas privadas brasileiras desenvolveram baixa capacidade tecnológica nesse período. 
A liberação da comercialização dos medicamentos genéricos a partir de 2000 criou uma nova dinâmica competitiva na indústria farmacêutica brasileira, possibilitando o desenvolvimento de empresas nacionais de maior porte (Moreira e Pitassi, 2013). Atualmente, 50\% das vendas de fármacos no Brasil são feitas pelos laboratórios brasileiros e há cinco empresas brasileiras entre as 10 maiores do ramo no país. A maior parte da produção local é de genéricos e é direcionada para o mercado interno, sendo exportada apenas uma pequena parcela, majoritariamente para a América Latina (Françoso e Strachman, 2013).

Uma característica distintiva da indústria farmacêutica brasileira é a presença de um conjunto de laboratórios públicos, cujas ações são direcionadas ao combate das chamadas doenças negligenciadas, tradicionalmente desconsideradas nas estratégias comerciais das farmacêuticas globais (Oliveira, Labra e Bermudez, 2006). Os laboratórios públicos produzem medicamentos, soros e vacinas voltados às necessidades do Sistema Único de Saúde (SUS), particularmente às políticas e programas de prevenção e combate das doenças infecciosas (Ribeiro, 2000). A maior parte dos medicamentos é comercializada diretamente para o Ministério da Saúde (MS). Logo, o bom desempenho do conjunto dos laboratórios públicos tem impacto direto na capacidade de o Estado brasileiro garantir melhores condições de saúde às populações carentes.

Em meados da década de 2000, o MS criou a Rede Brasileira de Produção Pública de Medicamentos (RBPPM), considerada um patrimônio nacional (Magalhães, Antunes e Boechat, 2011). A partir desse evento, percebe-se uma preocupação do MS em adotar mecanismos que levem à gestão integrada dos laboratórios públicos brasileiros. Se adotados na íntegra, os objetivos dessa rede, explicitados mais à frente, permitirão uma melhor coordenação, cooperação e planejamento da cadeia de suprimentos dos laboratórios públicos, entre si e entre os demais atores sociais e parceiros envolvidos, tais como as farmacêuticas privadas, as universidades e os centros de pesquisa.

Partindo das projeções de venda dos produtos em que se especializa, a cadeia de suprimentos de um laboratório farmacêutico inicia-se com a aquisição do fármaco (princípio ativo), dos insumos farmacêuticos, do material de acondicionamento e dos diferentes tipos de embalagem. À jusante, os laboratórios comercializam os medicamentos de venda livre diretamente para as farmácias. Já os medicamentos tarjados, que exigem prescrição, demandam uma etapa prévia de divulgação aos médicos e aos dentistas.

Em face dos eventos expostos, o parque industrial brasileiro de medicamentos desenvolveu uma capacidade restrita na produção dos insumos farmacêuticos obtidos das indústrias de química fina, os fármacos (Gadelha, Quental e Fialho, 2003). Portanto, importa-se a quase totalidade desses insumos, considerados os mais onerosos e críticos para a fabricação de medicamentos. Essa importação gera ineficiências na gestão da cadeia de suprimento (GCS) (Supply Chain Management - SCM, em inglês) dos laboratórios públicos e privados brasileiros (Bastos, 2005) e contribui negativamente para o déficit crônico que o Brasil vem apresentando ao longo das últimas décadas no Complexo Industrial da Saúde (CIS) (Scaramuzzo, 2013; Calixto e Siqueira Junior, 2008).

A partir da década de 1990, cresceram as evidências empíricas e teóricas de que uma boa GCS contribui para o desempenho de uma organização, independentemente do setor de atuação (Shahabuddin, 2011). O compartilhamento da informação proporcionada pela 
GCS ajuda a reduzir os níveis de estoques e os ciclos de tempo na cadeia (William, Germain e Birou, 2007). Defende-se que o sucesso de uma GCS está associado em parte ao uso de sistemas de informações (SI) que abranjam todas as empresas da cadeia (Kurien e Qureshi, 2011). Em face da importância dos laboratórios públicos, se pressupõe neste artigo que uma boa GCS pode contribuir para atuação conjunta desses laboratórios com vistas à melhor gestão dos recursos públicos destinados à melhora da saúde e à redução do crônico déficit no CIS brasileiro.

A relação entre o uso das tecnologias de informação e comunicação (TIC) e o desempenho da GCS vem sendo explorada há duas décadas na literatura científica (Rao, 2013; Zhang, Van Donk e Van Der Vaart, 2011; Salo e Karjaluoto, 2006), inclusive em alguns ramos de negócio no Brasil (Maçada, Feldens e Santos, 2007). Regra geral, as pesquisas indicam que o uso de TIC pode contribuir para uma boa GCS. A pesquisa bibliográfica realizada no âmbito deste estudo indica uma carência de estudos sobre a GCS no ramo farmacêutico brasileiro, em especial, em relação à contribuição das TIC. A pesquisa aqui apresentada situa-se no campo de estudo do uso de TIC em apoio GCS. Esta pesquisa estende esse campo de estudo buscando responder a seguinte questão: qual a contribuição que as TIC trazem para a integração da cadeia de suprimentos dos institutos de pesquisa públicos brasileiros? O objetivo deste artigo é investigar o uso pelos Laboratórios Farmacêuticos Oficiais Brasileiros das contribuições derivadas das Tecnologias da Informação e Comunicação (TIC), no sentido da integração da cadeia de suprimentos da RBPPM.

O artigo está organizado da seguinte forma. Na segunda seção, sob o título de referencial teórico, são apresentados: i) o conceito GCS e sua contribuição para as estruturas em rede de relacionamentos; ii) o conceito de TIC e sua utilização na GCS; iii) os laboratórios públicos brasileiros e os objetivos estabelecidos pelo MS para o funcionamento desses laboratórios; iv) a cadeia de suprimentos dos laboratórios públicos brasileiros. Na terceira seção, descrevemse os procedimentos metodológicos adotados para o trabalho de campo. Na quarta parte, apresentam-se e discutem-se os resultados das fases quantitativa e qualitativa da pesquisa de campo. Na quinta e última seção, são apresentadas as considerações conclusivas do estudo.

\section{Referencial teórico}

\subsection{Gestão da cadeia de suprimento (GCS)}

A construção de cadeias de suprimentos é vista como um passo indispensável para a obtenção de uma vantagem competitiva na velocidade exigida pela economia digital (Kurien e Qureshi, 2011). A emergência da GCS como campo teórico e prático está fortemente associada aos objetivos de sincronização e de coordenação de esforços entre a empresa central e seus parceiros de negócio (Rao, 2013), e muitos arcabouços de análise apoiam-se em conceitos, tais como confiança, complementariedade de recursos e investimentos específicos para a relação com os parceiros (Viana, Queiroz e Lima, 2013), conceitos estes oriundos da visão relacional (Dyer 
e Singh, 1998). A partir de meados de 2000, cresceram as evidências teóricas e empíricas de que a GCS assumiu uma complexa lógica de inter-relacionamentos em redes (networks, em inglês) comerciais e industriais (Håkansson e Persson, 2004).

O estudo de Salo e Karjaluoto (2006) observa que há vários conceitos descrevendo as cadeias de suprimentos e a GCS na literatura científica, variando de perspectivas lineares e mais restritivas de cadeias produtivas específicas (no limite, à díade) às estruturas em redes de relacionamentos verticais e horizontais envolvendo atores de vários níveis, incluindo as indústrias correlatas. Segundo o Council of Supply Chain Management Professionals (CSCMP), a GCS envolve as atividades usualmente associadas à logística integrada (compras, estocagem, movimentação de materiais, distribuição etc.) bem como o fluxo de materiais e informação entre parceiros de negócio. Apresenta-se a seguir o conceito de GCS proposto pelo CSCMP (2013:187), que será adotado nesse estudo: "envolve o planejamento e a gestão de todas as atividades associadas à logística interna e interorganizacional, bem como a coordenação e colaboração entre todos os parceiros da cadeia, sejam eles fornecedores, prestadores de serviço ou consumidores".

\subsection{Tecnologias de informação e comunicação (TIC) na GCS}

De acordo com Barbosa, Careta e Musetti (2007), as TIC são fundamentais para o desenvolvimento e a melhoria do desempenho das empresas que se envolvem em processos de integração. Turban e colaboradores (2010) evidenciam a dificuldade de gerenciar a cadeia de suprimentos complexa, tais como as que se estabelecem no ramo farmacêutico, sem a utilização de TIC. As TIC desempenham um importante papel pela sua capacidade de permitir que grandes quantidades de informação sejam compartilhadas ao longo da cadeia de suprimentos de forma rápida e segura (Marquez, 2010).

A TIC é uma tecnologia centrada no computador, que permite a coleta, o armazenamen-

to, o processamento e a comunicação da informação. É composta de hardware (por exemplo, computadores, terminais, roteadores, firewalls e smartphones) e software (por exemplo, sistemas operacionais, aplicativos e websites) (Turban et al., 2010). Sistemas de Informação (SI), um conceito mais amplo do que as TIC, são uma combinação de processos, informação, pessoas e TI, organizada para atingir objetivos de negócios, sendo fortemente dependente de fatores organizacionais para seu uso efetivo (Pitassi e Moreno, 2009). Adota-se neste estudo o conceito de TIC proposto por Ryssel, Ritter e Gemünden, (2004:198), dada a sua abordagem relacional dessas tecnologias: "envolve todas as formas de tecnologias usadas para criar, capturar, manipular, comunicar, trocar, apresentar e usar a informação em suas várias formas (dados de negócio, voz, imagens, filmes, apresentações multimídia, incluindo aquelas formas ainda não concebidas)".

O quadro 1 apresenta as ferramentas de TIC ou SI que foram identificadas na pesquisa bibliográfica e que são utilizadas na gestão da cadeia de suprimentos. 


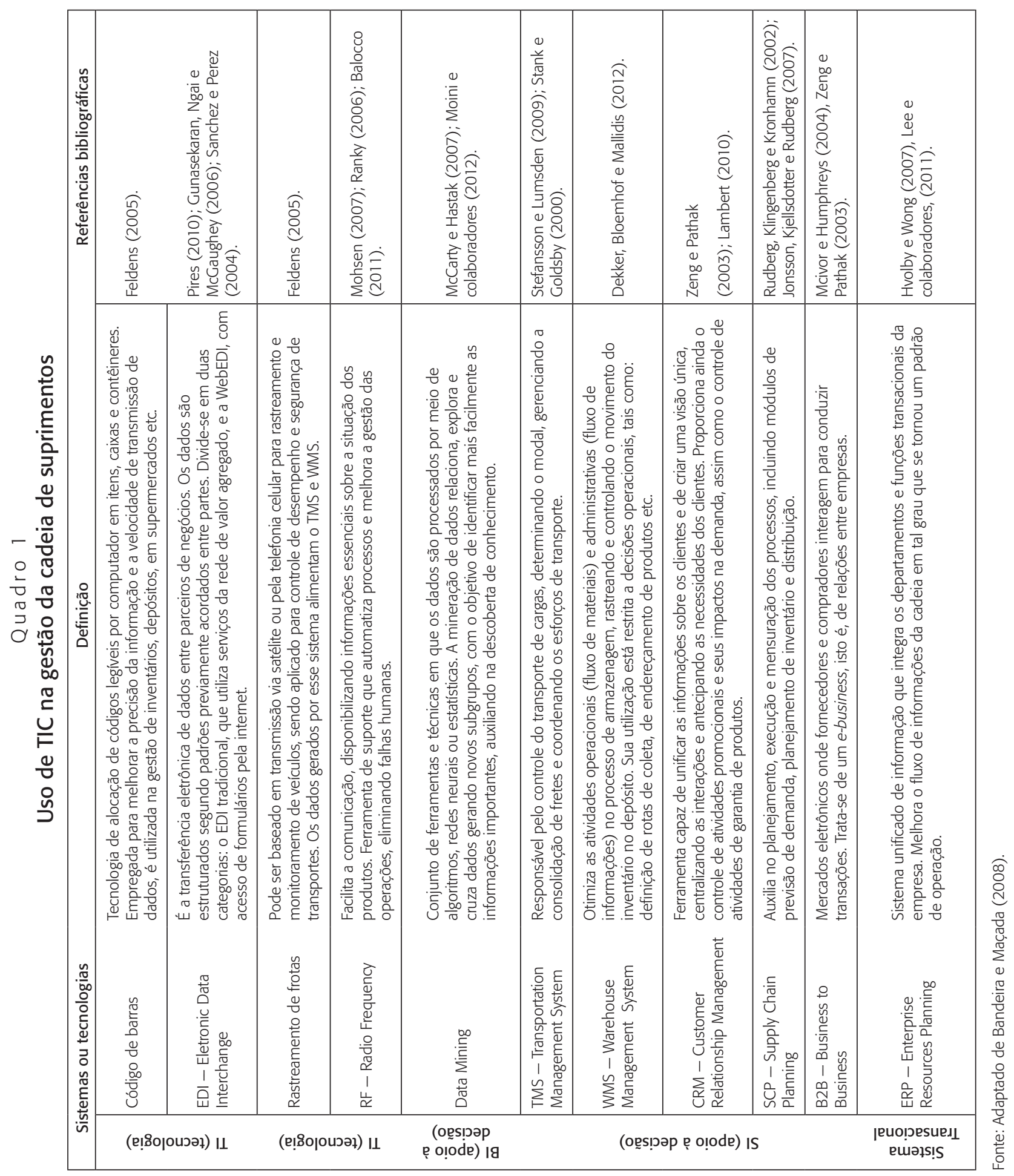




\subsection{Laboratórios farmacêuticos públicos brasileiros}

A cadeia produtiva na indústria farmacêutica constitui-se da etapa química fina, em que são sintetizados os princípios ativos (fármacos) e os aditivos, e da etapa farmacêutica, na qual se produz o medicamento final (Palmeira Filho e Pan, 2003). Todas as etapas de produção, tanto para laboratórios públicos quanto para privados, devem ser realizadas de acordo com a legislação vigente, a Resolução da Diretoria Colegiada (RDC) № 17, de 16 de abril de 2010, que define as Boas Práticas de Fabricação (BPF) de Medicamentos. A Agência Nacional de Vigilância Sanitária (Anvisa) exige o cumprimento desse regulamento, bem como o controle do processo produtivo, de modo a que o laboratório adquira ou mantenha o registro do medicamento produzido. As BPF abarcam as áreas de produção, manutenção, controle de qualidade, manuseio de materiais, armazenamento, distribuição, compras, tendo como objetivo oferecer medicamentos de qualidade, eficazes e seguros à população (Lachman, Lieberman e Kanig, 2010).

Uma característica peculiar da indústria farmacêutica no Brasil é a existência de um parque público de laboratórios voltados para a produção de medicamentos em nível nacional. Essa produção contribui para minorar o problema de suprimento de determinadas drogas e para reduzir os custos dos programas públicos de saúde, seja pela oferta de medicamentos a preços reduzidos, seja pelo efeito indutor e regulatório que exercem sobre os preços privados, como evidenciado nas negociações realizadas em 2001 pelo MS para a redução dos preços dos medicamentos contra a Aids, vendidos pelas Big Pharmas (Gadelha, Quental e Fialho, 2003; Oliveira, Labra e Bermudez, 2006).

A rede pública de laboratórios farmacêuticos vinculados à Associação de Laboratórios Oficiais do Brasil (Alfob) é formada por 21 laboratórios das esferas federal e estadual, vinculados ao MS, às Forças Armadas, às universidades públicas e às Secretarias de Saúde estaduais, sendo todos os medicamentos destinados ao setor público (Alfob, 2012). Pode-se observar na figura 1 a disposição geográfica de todos os laboratórios oficiais vinculados à Alfob.

Os laboratórios públicos vêm encontrando dificuldades na produção dos medicamentos em face dos problemas de qualidade dos insumos utilizados. Como lembram Buss, Carvalheiro e Casas (2008), toda aquisição no setor público de bem ou serviço é regida pela Lei no 8.666/1993, o que impõe diversas limitações, como não permitir manter a priori um fornecedor de matéria-prima cuja qualidade se mostrou adequada.

Outro problema relaciona-se aos equipamentos utilizados. Os equipamentos mais modernos, mais precisos e mais adequados para manutenção da qualidade lote a lote demandam especificações que extrapolam as características técnicas preconizadas na lei, gerando muitas vezes a necessidade de substituição ou reprocessamento da matéria-prima para que a qualidade do medicamento seja garantida (Buss, Carvalheiro e Casas, 2008). Esse problema acaba prejudicando e atrasando o andamento da produção.

Outros desafios também citados pelos autores são: i) espaço físico limitado para ampliação e adequação da área produtiva às normas sanitárias; ii) gestão do conhecimento desestruturada ou mesmo inexistente; iii) ausência de um sistema de gestão integrado na 
maioria dos laboratórios; iv) dificuldade de retenção de recursos humanos, já que a defasagem salarial em relação ao mercado é grande, principalmente na área de pesquisa e desenvolvimento (P\&D).

Figura 1

Demonstração geográfica dos Laboratórios Farmacêuticos Oficiais vinculados à Alfob

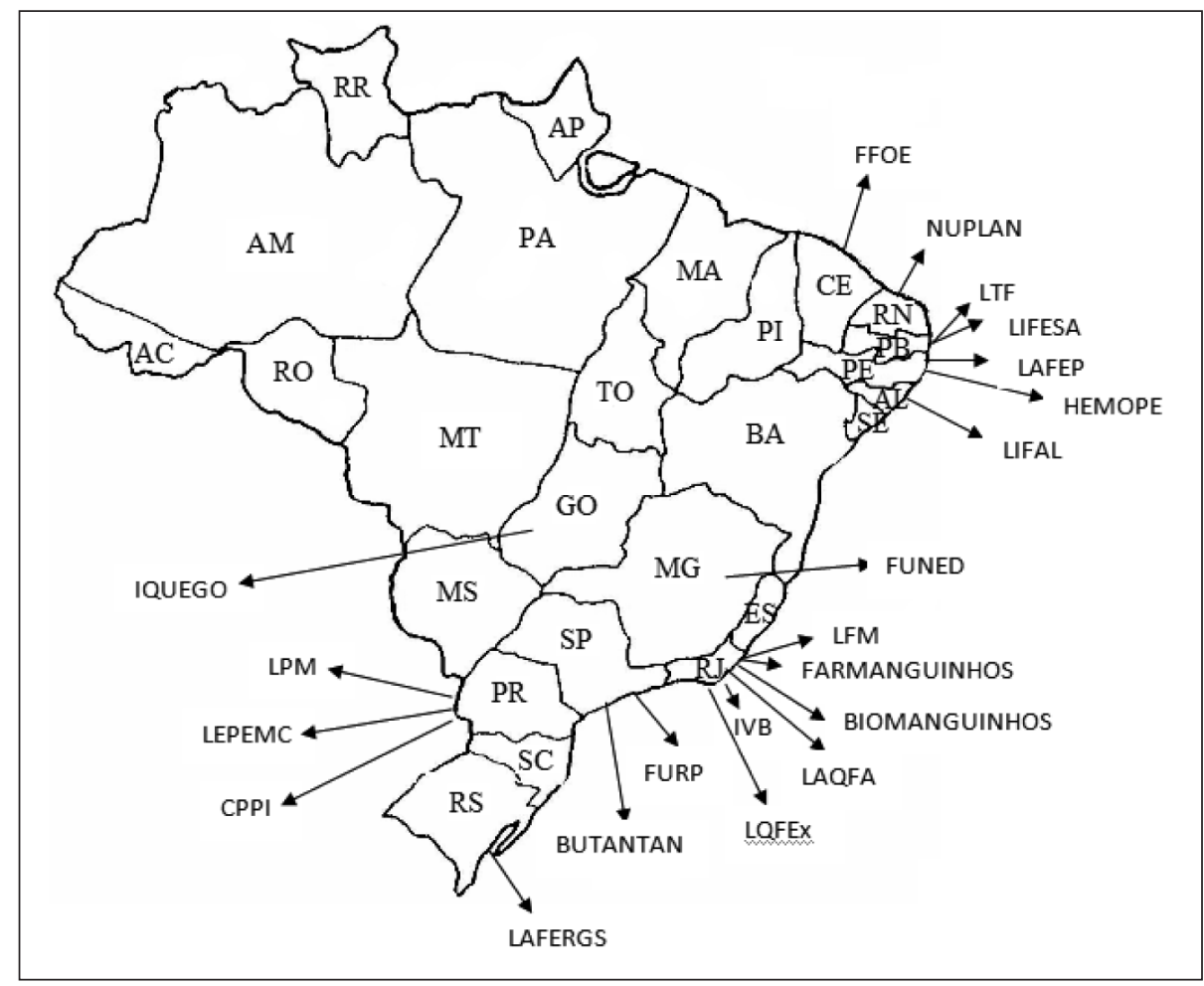

Fonte: Adaptado de Magalhães, Antunes e Boechat (2011).

Para melhorar o desempenho do conjunto dos laboratórios públicos, o MS criou a Rede Brasileira de Produção Pública de Medicamentos (RBPPM), por meio da publicação da Portaria GM/MS no 2.438, de 7 de dezembro de 2005. No art. 3ํ dessa portaria estão descritos os objetivos fundamentais dessa rede, o que ajudará o leitor na avaliação da potencial contribuição da GCS, para os objetivos descritos a seguir:

I- desenvolver ações que visem à reorganização do sistema oficial de produção de medicamentos, com a adoção de estratégias para a racionalização da produção oficial e para a sua aproximação às necessidades e prioridades do Sistema Único de Saúde; 
II- desenvolver ações coordenadas e cooperadas que visem ao suprimento de medicamentos demandados pelo Sistema Único de Saúde;

III- adotar, em seu âmbito, ações coordenadas que visem ao suprimento regular e adequado de matérias-primas e de insumos necessários à produção oficial de medicamentos;

IV- desenvolver ações que visem à garantia de fornecimento de medicamentos aos programas públicos considerados estratégicos, principalmente daqueles cuja produção envolve exclusivamente a capacidade instalada do parque fabril oficial;

V- adotar, em seu âmbito, medidas estruturantes para os laboratórios farmacêuticos oficiais integrantes da Rede, bem como estratégias conjuntas para o aprimoramento e otimização da gestão;

VI— desenvolver ações que visem à capilarização das iniciativas de fomento ao desenvolvimento tecnológico e das ações de pesquisa e desenvolvimento;

VII- desenvolver ações voltadas à ampliação e à organização das interfaces no âmbito dos acordos internacionais e de transferência de tecnologia adotados pelo País, nos quais estejam envolvidos os laboratórios farmacêuticos oficiais integrantes da rede;

VIII— desenvolver ações de fortalecimento do desenvolvimento regional, nas áreas de abrangência dos laboratórios farmacêuticos oficiais integrantes da Rede.

Por conseguinte, a adoção de técnicas e ferramentas modernas de gestão, como a utilização da GCS e das ferramentas de TIC, torna-se imprescindível para que os laboratórios trabalhem em redes integradas, visando o acompanhamento das evoluções tecnológicas do setor farmacêutico e possibilitando que a cadeia de suprimentos funcione de forma integrada entre os laboratórios, e, assim, otimizando todo o processo produtivo para o atendimento da demanda da sociedade brasileira.

\subsection{GCS nos laboratórios públicos brasileiros}

A cadeia de suprimentos do setor farmacêutico compreende desde os fornecedores de matérias-primas até o consumidor final, incluindo os laboratórios farmacêuticos responsáveis pela fabricação e entrega dos medicamentos (Sampaio e Csillag, 2010). O relacionamento colaborativo na indústria farmacêutica é essencial para viabilizar a coordenação das diversas áreas, tais como logística, desenvolvimento, qualidade, compartilhamento de informações e aprendizado conjuntos (Kumar, 1996). Dessa maneira, o laboratório farmacêutico pode integrar sua cadeia de suprimentos por meio dos relacionamentos colaborativos dentro e fora de sua fronteira organizacional, inclusive com vistas ao desenvolvimento conjunto de novas drogas (Chiaroni, Chiesa e Frattini, 2008).

A figura 2 ilustra os elos existentes na cadeia de suprimentos dos Laboratórios Farmacêuticos Oficiais. A seguir apresenta-se uma breve descrição da figura desenvolvida a partir do artigo original de Maradei Jr. (2008). 
Figura 2

Cadeia de suprimentos dos laboratórios farmacêuticos oficiais

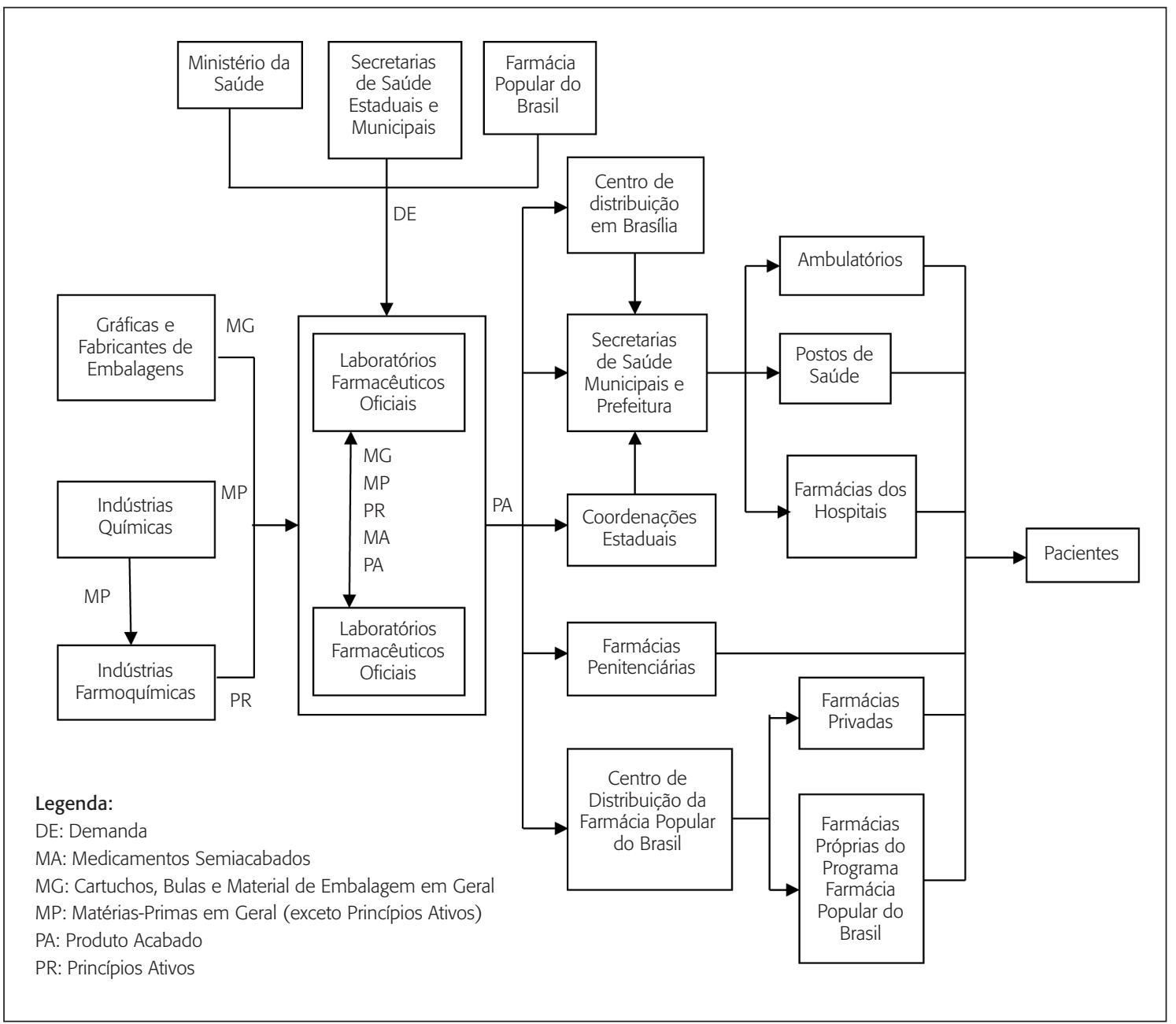

Fonte: Adaptado de Maradei Junior (2008).

Nos Laboratórios Farmacêuticos Oficiais, a demanda de medicamentos é enviada pelos Programas do MS, Programa Farmácia Popular do Brasil (Programa do MS gerenciado pela Fiocruz) e Secretarias de Saúde Estaduais e Municipais (consideradas vendas diretas).

Os medicamentos destinados ao atendimento dos Programas do Ministério da Saúde são enviados para o centro de distribuição localizado em Brasília, para as coordenações estaduais e para as Secretarias de Saúde Municipais e Prefeituras, de acordo com as pautas entregues aos laboratórios pelo próprio MS. Cada pauta contém o local de entrega e a quantidade de medicamentos para o laboratório realizar a distribuição. Vale ressaltar que o centro de distribuição localizado em Brasília serve como estoque estratégico para atender eventuais 
faltas de medicamentos dos municípios e das prefeituras. Já no Programa específico denominado Programa Penitenciário, os medicamentos são enviados diretamente para as farmácias penitenciárias. As vendas realizadas diretamente com as Secretarias de Saúde Estaduais e Municipais são entregues para as próprias secretarias solicitantes, para posteriormente serem distribuídas para os ambulatórios, postos de saúde e farmácias dos hospitais.

Os medicamentos destinados ao Programa Farmácia Popular do Brasil são primeiramente enviados para um centro de distribuição e posteriormente para as farmácias próprias desse programa, ou para farmácias particulares que possuem convênio com o programa, onde o paciente, com a apresentação da receita médica, pode adquirir, dependendo do medicamento, com preços reduzidos ou gratuitamente. Os laboratórios públicos não fabricam amostras grátis, portanto não existe distribuição de medicamentos diretamente para os médicos.

\section{Metodologia}

Tendo em vista o objetivo proposto neste trabalho, a pesquisa empírica foi conduzida por meio de uma abordagem integrativa, triangulando os métodos quantitativos e qualitativos. Vergara (2005) qualifica os objetivos de uma pesquisa científica em dois aspectos distintos: quanto aos fins e quanto aos meios. Quanto aos fins, a pesquisa foi classificada como descritiva e explicativa, pois teve como proposta descrever quais são as ferramentas de TIC existentes nas atividades da cadeia de suprimentos dos laboratórios farmacêuticos oficiais e explicar como elas estão sendo utilizadas, além de evidenciar sua contribuição. Quanto aos meios, foi classificada como pesquisa de campo e pesquisa bibliográfica. A unidade de análise da presente pesquisa são as TIC utilizadas na cadeia de suprimentos dos Laboratórios Farmacêuticos Oficiais Brasileiros.

Na primeira fase da pesquisa de campo, os dados foram coletados por meio de questionários enviados por e-mail para cada gestor de Logística dos laboratórios membros da Alfob. Essa primeira fase teve por objetivo levantar questões e aspectos que seriam aprofundados na fase qualitativa do estudo. Apesar de existirem 21 laboratórios, apenas 13 continuavam com suas produções ativas. O questionário foi elaborado de acordo com dados obtidos no referencial teórico, tendo como referência a pesquisa de Carneiro (2005). Dos 13 questionários enviados por e-mail, apenas um laboratório não respondeu, por considerar as informações sigilosas. Todos os outros 12 questionários foram retornados e validados.

Na segunda parte da pesquisa empírica, a coleta de evidências foi realizada por meio de entrevistas semiestruturadas seguindo um roteiro básico elaborado de acordo com os dados obtidos no referencial teórico, já que na revisão de literatura não foi encontrado nenhum instrumento de coleta de evidências que pudesse ser replicado nesta pesquisa. Foram entrevistados seis profissionais, sendo um do setor de logística e outro da área de TI de três laboratórios que apresentaram as maiores discrepâncias entre a quantidade de TIC utilizadas e a contribuição que essas ferramentas traziam para a integração entre os laboratórios. 
Os dados coletados pelos questionários foram tratados utilizando estatística descritiva e correlação múltipla. Já as evidências coletadas nas entrevistas semiestruturadas foram tratadas por meio da análise de conteúdo. Após a realização de toda a pesquisa empírica, foi possível realizar uma triangulação de dados utilizando as diferentes fontes de coleta, tais como: pesquisas bibliográficas, questionários, entrevistas e observação direta. Essa triangulação permitiu assegurar maior validade e credibilidade à pesquisa de campo realizada.

\section{Apresentação e análise dos resultados}

\subsection{Análise quantitativa}

A maior parte dos laboratórios produzia medicamentos orais, sendo as principais classes terapêuticas os anti-hipertensivos, os tuberculostáticos e os antirretrovirais. Cinco desses laboratórios possuíam aproximadamente mil funcionários ou mais e apenas dois laboratórios contavam com menos de 100 colaboradores.

De acordo com as respostas dos participantes em relação às ferramentas listadas nos questionários, os laboratórios utilizavam diversos SI ou TIC de uso direto ou indireto na GCS, mas constatou-se que essas ferramentas, de uma forma geral, não traziam grandes contribuições para a execução das atividades do setor. Como pode ser observado na tabela 1, as ferramentas que mais contribuíam eram o ERP, o MRPI e o Rastreamento de Frotas, ficando no intervalo entre pouca e média contribuição.

Tabela 1

Nível de contribuição de cada sistema/tecnologia de informação utilizado

\begin{tabular}{|c|c|c|c|c|c|c|c|c|c|c|c|c|}
\hline \multirow{3}{*}{ LABORATÓRIO } & \multicolumn{12}{|c|}{ NÍVEL DE CONTRIBUIÇÃO DO SISTEMA/TECNOLOGIA DE INFORMAÇÃO } \\
\hline & \multicolumn{9}{|c|}{ USO INDIRETO DA GCS } & \multicolumn{3}{|c|}{ USO DIRETO GCS } \\
\hline & Código Barras & EDI & Rastr. Frotas & TMS & WMS & CRM & SCP & $\mathrm{B} 2 \mathrm{~B}$ & ERP & MRPI & MRPII & APS \\
\hline Biomanguinhos & & & & & 3 & & & & 3 & 3 & & \\
\hline Butantan & 0 & & 1 & & & & 2 & & & & & \\
\hline CPPI & & & 3 & & & & & & & & & \\
\hline Farmanguinhos & & & & & & & & & 2 & 3 & & \\
\hline Funed & & & 3 & & 2 & & & & 3 & 3 & & \\
\hline Furp & 3 & & 3 & & & & & & 3 & 3 & & \\
\hline Iquego & & & 2 & & & 2 & 3 & 3 & 3 & & & 2 \\
\hline IVB & 2 & & 2 & & 2 & & 2 & & 2 & 3 & 2 & 3 \\
\hline Lafepe & & & & & 1 & & & & 1 & 1 & & \\
\hline \multicolumn{13}{|l|}{ Laqfa } \\
\hline LFM & & 3 & & 1 & 3 & 2 & 2 & 3 & 3 & 3 & 2 & 2 \\
\hline Nuplam & 0 & 2 & & & & & & 3 & 0 & & & \\
\hline Média & 0,42 & 0,42 & 1,17 & 0,08 & 0,92 & 0,33 & 0,75 & 0,75 & 1,67 & 1,58 & 0,33 & 0,64 \\
\hline
\end{tabular}

Fonte: Elaboração própria. 
Os valores numéricos presentes na tabela correspondem à intensidade da contribuição que o SI ou TIC traz na execução das atividades do setor, variando de nenhuma (0) a alta (3). Foi considerada que a sua não utilização era equivalente à sua utilização, porém com contribuição nula. Portanto, as médias foram calculadas atribuindo-se o valor "0" também para os espaços em branco, que correspondem à não utilização.

Utilizou-se a escala Likert variando de 1 a 7 para verificar o nível de integração interna e externa por laboratório, considerando integração interna como a logística integrada do laboratório e integração externa como a cadeia de suprimentos dos laboratórios. Observou-se, conforme os valores médios por laboratório expostos na tabela 2, que os laboratórios IVB e Butantan eram os que apresentavam os maiores níveis de integração interna, enquanto o laboratório Nuplam era o que apresentava o maior nível de integração externa. O laboratório CPPI foi o que apresentou menor nível de integração, tanto interna como externa. Os valores entre 0 e 3 foram considerados integração baixa, valores acima de 3 até 5, integração moderada, e valores acima de 5 até 7 , integração alta.

Tabela 2

Média do nível de integração dos laboratórios (interna e externa)

\begin{tabular}{|lccc|}
\hline \multirow{2}{*}{ LABORATÓRIO } & \multicolumn{3}{c|}{ MÉDIA DO NÍVEL DE INTEGRAÇÃO } \\
\cline { 2 - 4 } & Logística Integrada & GCS & Média por Laboratório \\
\hline Biomanguinhos & 3,95 & 4,67 & 4,31 \\
Butantan & 5,40 & 3,73 & 4,56 \\
CPPI & 3,05 & 2,83 & 2,94 \\
Farmanguinhos & 4,25 & 5,35 & 4,80 \\
Funed & 3,15 & 4,29 & 3,72 \\
Furp & 4,84 & 4,67 & 4,75 \\
Iquego & 4,65 & 5,35 & 5,00 \\
IVB & 5,50 & 4,65 & 5,07 \\
Lafepe & 3,75 & 5,33 & 4,54 \\
Laqfa & 3,61 & 4,35 & 3,98 \\
LFM & 4,95 & 5,06 & 5,00 \\
Nuplam & 4,13 & 6,00 & 5,06 \\
Média por Categoria & 4,27 & 4,69 & \\
\hline
\end{tabular}

Fonte: Elaboração própria.

Foi utilizada a correlação múltipla para verificar a relação entre o uso de cada ferramenta e o nível de integração dos laboratórios, para tentar inferir a importância das ferramentas na integração. Os resultados podem ser visualizados na tabela 3, de onde se pode inferir que a ferramenta SCP era, na opinião dos respondentes, a que mais contribuía para a logística integrada do laboratório. Já as ferramentas B2B e EDI pareceram ser as que mais contribuíam 
para a integração entre os laboratórios (GCS). Em termos de contribuição de uma forma geral, o SCP evidenciou ser o mais importante e o Rastreamento de Frotas o que menos contribuía.

Tabela 3

Correlação entre a utilização das ferramentas e o nível de integração

\begin{tabular}{|cccccccccccccc|}
\hline \multirow{3}{*}{ Tipo de Integração } & \multicolumn{1}{c|}{ Uso Indireto na GCS } & \multicolumn{1}{c|}{ Uso Direto do GCS } \\
& $\begin{array}{c}\text { Código } \\
\text { Barras }\end{array}$ & EDI & $\begin{array}{c}\text { Rastr. } \\
\text { Frotas }\end{array}$ & TMS & WMS & CRM & SCP & B2B & ERP & MRPI & MRPII & APS \\
Entre os Labs. & 0,47 & 0,20 & $-0,08$ & 0,26 & 0,07 & 0,30 & 0,71 & 0,23 & 0,20 & 0,19 & 0,55 & 0,60 \\
& $-0,02$ & 0,40 & $-0,53$ & 0,14 & 0,07 & 0,29 & 0,07 & 0,56 & 0,29 & 0,16 & 0,09 & 0,11 \\
\hline
\end{tabular}

Fonte: Elaboração própria.

Alguns laboratórios revelaram utilizar mais ferramentas do que outros e, conforme já foi apresentado, foram identificados laboratórios com níveis de integração bem diferentes. Mas, de uma maneira geral, não houve discrepância entre as quantidades de TIC utilizadas em cada laboratório e seu nível de integração, como pode ser observado no gráfico 1: os laboratórios que utilizavam mais TIC tendiam a ser os de maior nível de integração. No entanto, alguns laboratórios apresentaram alguma discrepância nessa relação.

Gráfico 1

Média de integração por quantidade de TICs utilizadas

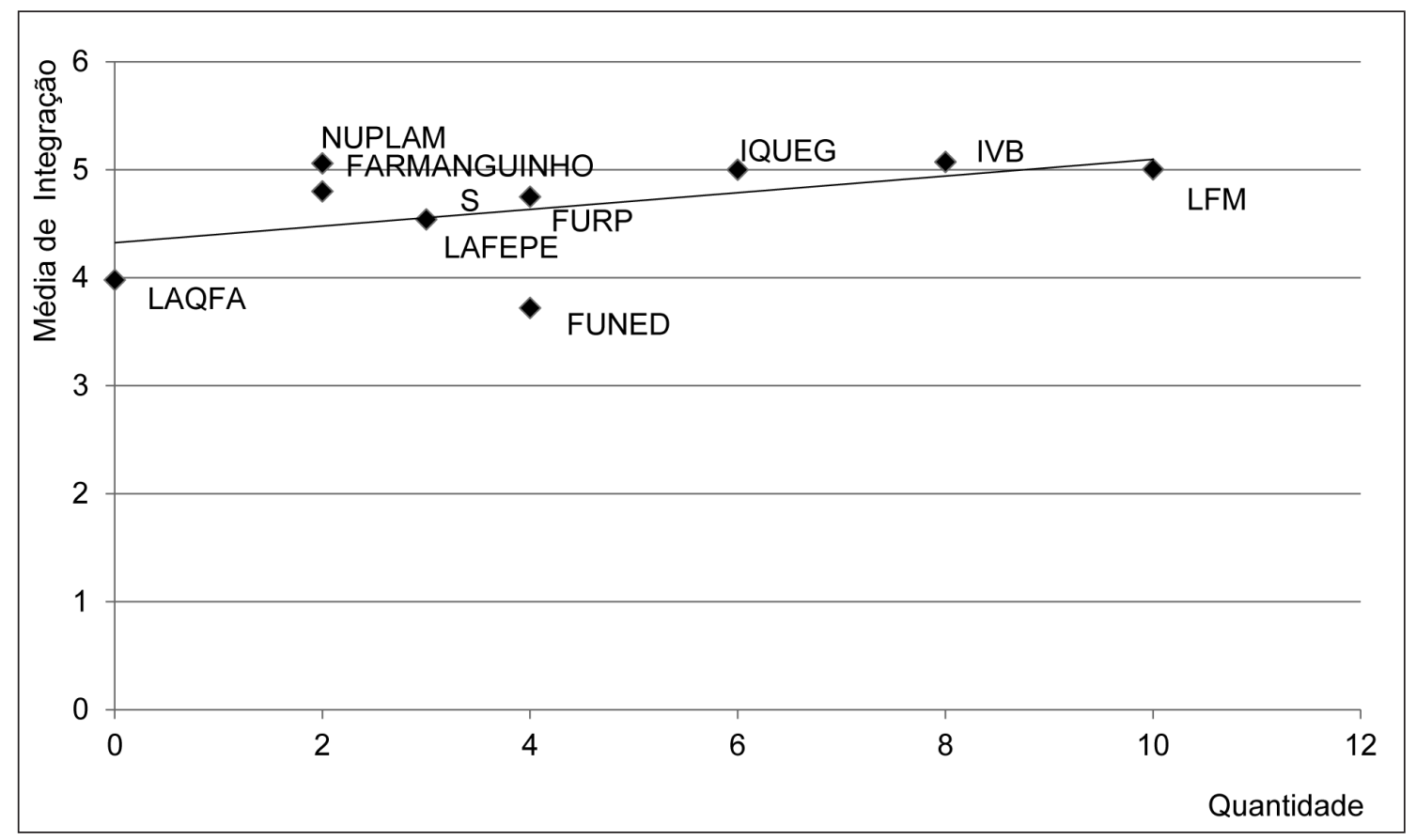

Fonte: Elaboração própria. 
O gráfico mostra que o laboratório Funed é o que apresenta a maior discrepância. Por esse motivo, esse foi um dos laboratórios escolhidos para aprofundar a pesquisa pela utilização da abordagem qualitativa. O laboratório Laqfa também foi escolhido para a pesquisa qualitativa por apresentar certa discrepância entre a quantidade de ferramentas utilizadas e o nível de integração, e pelo fato de o laboratório não utilizar nenhum tipo de ferramenta de TIC. O terceiro laboratório escolhido foi o IVB pelo fato de possuir oito ferramentas de TIC e de ter a maior média de integração comparando com os outros laboratórios pesquisados. Apesar de o laboratório Nuplam apresentar certa discrepância, optou-se pelo laboratório IVB pelo fato de os outros dois laboratórios escolhidos (Funed e Laqfa) já representarem uma amostra daqueles que utilizam pouca ou nenhuma TIC.

\subsection{Análise qualitativa}

As entrevistas nos três laboratórios públicos selecionados confirmaram que a maior parte da demanda de medicamentos é proveniente do MS. Essa demanda era definida por meio de reuniões sistemáticas entre a presidência ou a diretoria do laboratório com os representantes do MS. As demandas do MS eram discutidas em reuniões interdepartamentais e, em alguns casos, identificava-se a necessidade da produção de novas drogas com vistas à redução das importações. Os depoimentos seguintes evidenciam esse processo:

Depois que a presidência tem as informações sobre as demandas, ela se reúne com os gestores de diversos setores, inclusive o PCP (Programação e Controle da Produção), e passa as informações sobre as quantidades e os prazos de entrega dos medicamentos que foram acordados. Quando surge uma demanda extra ao longo do ano, a presidência nos informa para que possamos providenciar a compra de matérias-primas e planejar a produção. (assistente administrativo de PCP - Funed)

Nós procuramos saber a relação dos medicamentos que o Ministério compra de fora, que não são produzidos no Brasil, para analisar quais desses medicamentos nós temos condições de produzir e, então, começamos o processo de desenvolvimento de fabricação para oferecer o medicamento ao Ministério a um custo menor do que eles compram lá fora. Nós demoramos em média três anos para começar o processo de venda. (assessor de PCP — IVB)

Os entrevistados informaram que os laboratórios não tinham o hábito de terceirizar parte da fabricação, como defende a literatura de GCS. Quando não havia capacidade suficiente para atender a demanda, o medicamento era comprado já pronto de outro laboratório público ou privado. No entanto, a narrativa a respeito de uma experiência de terceirização traz indícios do potencial da aplicação da GCS:

Só teve uma vez que nós terceirizamos parte da produção. Foi um caso pontual de emergência, em 2010, que precisamos produzir o medicamento Oseltamivir devido ao risco de epidemia de 
Gripe Suína e Gripe Aviária. Cada laboratório oficial produziu parte do medicamento para agilizar o processo de produção. Foi uma parceria entre nós, o Laboratório do Exército, Laboratório da Marinha e Laboratório de Farmanguinhos. (chefe da subdivisão de Planejamento — Laqfa)

O MS possuía um sistema denominado Sislog, onde parte das informações precisava ser preenchida por funcionários dos laboratórios. Tal fato reforça a evidência do grau de importância do MS na etapa inicial da cadeia de suprimentos. O depoimento a seguir explica o papel do Sislog:

Depois que o termo de cooperação é assinado, o Ministério alimenta o sistema Sislog (Sistema de Logística do Ministério da Saúde), onde o laboratório consegue visualizar os medicamentos a serem entregues assim como o cronograma de entregas. O setor de Contratos visualiza e alimenta esse sistema com as quantidades que foram entregues ao Ministério. (chefe da subdivisão de Planejamento - Laqfa)

Nenhum dos três laboratórios entrevistados alegou possuir algum tipo de SI para auxiliar nas decisões de produzir, terceirizar ou comprar o medicamento já pronto. Verificou-se que dois laboratórios possuíam contratos de transferência de tecnologia por meio de Parcerias de Desenvolvimento Produtivo (PDPs), nas quais os laboratórios públicos gradativamente iam adquirindo o domínio de produção, como pode ser visto no depoimento a seguir:

No momento, a Funed tem um contrato de transferência de tecnologia através de um consórcio com dois laboratórios privados. Com a transferência de tecnologia, gradativamente, nós vamos tendo o domínio maior da produção e aos poucos vamos produzindo também. Tem um medicamento que no passado era todo produzido por esses laboratórios do consórcio. Esse ano, eles estão fabricando e nós já estamos embalando. A previsão é de que no próximo ano todas as etapas de produção deste medicamento sejam feitas aqui. (assistente administrativo de PCP - Funed).

Apesar de ficar evidente a troca de informações entre laboratórios públicos e privados, percebe-se que não existia um sistema de gestão que auxiliasse esse processo. Os três laboratórios estudados realizavam o Planejamento Estratégico da Produção, o Plano-Mestre de Produção e a Programação da Produção por meio de planilhas de Excel, utilizando um sistema, denominado pelos entrevistados como ERP, para a coleta de informações, como pode ser visto na resposta seguinte:

Nós utilizávamos os sistemas MRPI e MRPII, imprimíamos tudo na impressora matricial. Depois que a gente adquiriu impressoras mais modernas, não conseguimos mais imprimir esses sistemas, então nós passamos a utilizar só o Excel. No Excel eu faço uma planilha, como o MRP, e coloco a demanda, quantidade de medicamento em estoque, capacidade de produção e outras informações. (assessor de PCP — IVB) 
Os laboratórios investigados tinham o hábito de emprestar e receber emprestado matérias-primas de outros laboratórios públicos. Eles trocavam informações por e-mail informando os materiais que não seriam utilizados até o vencimento. O depoimento a seguir evidencia a distância das práticas adotadas dos processos de GCS descritos na literatura:

Na prática, o que acontece, é quando temos uma necessidade emergencial por determinado material, nós entramos em contato com os laboratórios para verificar se alguém pode nos emprestar. Alguns laboratórios mandam uma relação dos materiais que estão disponíveis e, se estivermos precisando desse material com urgência, nós solicitamos o empréstimo, mas nunca deixamos de fazer um pedido de compra pensando no empréstimo de outro laboratório. (chefe da subdivisão de Planejamento — Laqfa).

Apesar das evidências de alguma troca de informações e de materiais entre os laboratórios estudados, o processo de comunicação não era sistemático e ocorria via e-mail. Além disso, verificou-se que os laboratórios não realizavam compra conjunta, o que, de acordo com a teoria estudada, possibilitaria a redução do custo dos materiais ou dos serviços contratados. Verificou-se que, nos casos estudados, os atrasos nas entregas dos medicamentos não eram frequentes e, quando ocorriam, normalmente não passavam de cinco meses.

Os entrevistados alegaram que, caso o laboratório não tivesse um sistema informatizado, a Anvisa suspenderia os registros dos medicamentos e o laboratório ficaria proibido de produzir. Apesar de os entrevistados alegarem que o sistema ERP atendia parcialmente às necessidades operacionais e às necessidades dos órgãos reguladores, observou-se que esse sistema apresentava algumas falhas graves, típicas de sistemas de silos funcionais. De fato, os sistemas encontrados não podem ser considerados, do ponto de vista da taxonomia padrão, um ERP, como pode ser visto na resposta seguinte:

De acordo com o conceito, o ERP é uma integração como um sistema único. Apesar do nosso sistema ter o nome de ERP, ele não atende ao conceito seguindo a visão da informática. O nosso sistema tem a área de compras, financeiro e outras áreas, mas essas áreas não se integram com a produção. Então, apesar do nome, de acordo com as definições, esse sistema não é um ERP. Ele foi criado internamente, sem uma metodologia definida e sem profissionais qualificados. Além disso, a rotatividade de funcionários na área de TI é muito grande por causa do salário baixo que é pago aqui na Funed. (chefe do serviço de desenvolvimento e administração de software — Funed)

Nos processos de PCP, tais como plano mestre e sequenciamento, as planilhas de Excel ainda eram muito utilizadas nos laboratórios estudados. Embora os gestores entrevistados denominassem essas planilhas de sistema, de acordo com a definição de SI aqui adotada, um aplicativo desenvolvido em Excel não deve ser considerado um SI. Em face das prováveis dificuldades de conduzir processos mais sofisticados com o apoio de plataformas Office, os gestores reconheceram que era necessário implantar um SI mais atual, que integrasse os setores da organização, como pode ser visto na resposta seguinte: 
O sistema utilizado no momento é antigo, difícil de fazer mudanças e melhorias (...) acho que ajudaria bastante se tivéssemos um novo sistema ERP moderno que incluísse todas as informações que nós colocamos em Excel e que fizesse a interface com todos os setores. (chefe da subdivisão de Planejamento — Laqfa)

Dos três gestores de TI dos laboratórios entrevistados, um alegou que estaria providenciando a compra de um novo sistema ERP, outro comentou que estava implantando melhorias no sistema já existente, e o terceiro disse que estava estudando a implantação de um novo sistema, mas que provavelmente não seria um ERP. Percebe-se que os gestores pensavam em SI individuais para cada laboratório, além de não saberem exatamente qual seria o melhor tipo de sistema a ser implantado para apoiar a GCS, como sugere a fala a seguir: "O novo sistema a ser implantado não necessariamente seria um ERP, mas sim um sistema que atendesse toda a produção, em todos os quesitos, inclusive quanto às regras e normas que devem ser seguidas de acordo com as exigências da Anvisa" (chefe do serviço de desenvolvimento e administração de software - Funed).

\section{Conclusões}

Motivado pela decisão do MS de criar a RBPPM, o objetivo deste artigo era investigar o uso pelos Laboratórios Farmacêuticos Oficiais Brasileiros das contribuições derivadas das Tecnologias da Informação e Comunicação (TIC), no sentido da integração da cadeia de suprimentos da RBPPM.

Em primeiro lugar, a análise empreendida no âmbito deste estudo evidenciou que os objetivos descritos na criação da RBPPM, cujo alcance poderia ser facilitado pela adoção dos atributos da GCS pela rede capitaneada pelo MS, ainda são incipientes e erráticos. Quando presentes, alguns desses atributos, tais como a terceirização de parte da produção de medicamentos para outro laboratório público e a prática de empréstimos de matérias-primas entre eles, decorreram de uma decisão oportunista. Características mais profundas de redes de parcerias, em linha com uma visão de GCS de corte relacional, tais como investimentos específicos para a RBPPM e especialização de produção em função do perfil de cada parceiro, particularmente no caso das universidades públicas, estavam ausentes das evidências coletadas.

Em resposta direta ao problema desta pesquisa, o estudo demostrou que, apesar das evidências teóricas e empíricas a respeito da capacidade das TIC de integrar processos, amplamente retratadas na literatura científica, os laboratórios públicos brasileiros ainda fazem pouco uso das tecnologias aqui estudadas, tanto na logística integrada quanto na GCS, e o desempenho das poucas ferramentas encontradas revelou-se incipiente e insatisfatório. É bem provável que essa evidência seja uma decorrência natural do fato de que a RBPPM não utilizava uma abordagem de GCS na época em que esta pesquisa foi realizada.

Por meio da triangulação dos dados, coletaram-se indícios de que os laboratórios não possuíam todas as TIC que eles alegaram utilizar na primeira fase da pesquisa (questionários), 
embora essa constatação não possa ser generalizada, já que a pesquisa qualitativa foi realizada em apenas três laboratórios. Também se verificou que alguns entrevistados chamavam de MRPI, MRPII e APS rotinas desenvolvidas em planilhas de Excel, cujas limitações na integração de processos são amplamente reconhecidas na literatura e prática de gestão de SI.

Essa divergência quanto à utilização de TIC pode ter ocorrido por: i) falta de conhecimento a respeito da TIC descrita no questionário; ii) por considerarem planilhas de Excel ferramentas de TIC; iii) terem respondido o questionário de acordo com as TIC utilizadas nos laboratórios privados participantes das PDPs, já que parte da produção de alguns medicamentos é feita por esses laboratórios.

Há um amplo consenso entre teóricos e gestores de que os ERP contribuíram para que as organizações superassem a visão de silos funcionais, reduzindo a necessidade de reunir diferentes fragmentos de informações gerados por suas várias atividades e divisões. Verificou-se nos laboratórios investigados que, apesar da alegada existência do ERP, muitas informações ainda eram tratadas em uma visão de silos verticais, com rotinas geradas por planilhas de Excel, que impossibilitavam a integração dos processos na dinâmica exigida pela economia digital em geral e pelas estruturas em rede que hoje predominam na indústria farmacêutica global.

Além disso, os entrevistados consideravam que o ERP seria suficiente para atender todas as atividades de logística integrada, inclusive aquelas relacionadas ao PCP, desde que ele fosse um sistema confiável e que os módulos dos outros setores ou departamentos também estivessem incluídos no SI. Um possível motivo para a incompreensão dos limites e papéis de sistemas transacionais, como é o caso do ERP, e os sistemas de apoio a decisão, usualmente aplicados no PCP, pode ser a falta de conhecimento, por parte dos entrevistados, das TIC existentes na gestão da cadeia de suprimentos. Isso parece explicar por que não foi observado nenhum interesse por implantação de sistemas interorganizacionais, com algoritmos matemáticos mais sofisticados.

As falas dos entrevistados trazem fortes indícios de que, nos laboratórios investigados, os SI ainda chegavam apenas ao nível transacional. Claramente, os sistemas haviam sido desenvolvidos para apoiar as atividades rotineiras dos laboratórios, e as planilhas eletrônicas criadas em Excel cobriam as lacunas nos processos que exigiam o apoio às decisões de configuração dos planos mestres e sequenciamento da produção.

Apesar de a pesquisa indicar a existência de algum tipo de relacionamento pontual entre os laboratórios públicos, a pesquisa mostrou que a integração entre os laboratórios também era pequena, não existindo nenhum tipo de sistema que integrasse os laboratórios públicos em uma lógica de redes de suprimentos. A triangulação com a pesquisa bibliográfica permite argumentar que, caso fossem adotados pacotes integrados de gestão mais atualizados, baseados na WEB, os laboratórios públicos poderiam ter maior facilidade para integrar não apenas sua logística interna, mas também aos processos transacionais dos parceiros presentes em suas cadeias de suprimentos, avançando um pouco mais em direção aos objetivos da RBPPM.

$\mathrm{Na}$ época em que este estudo foi conduzido, cada laboratório público tinha seu próprio sistema com vistas a atender prioritariamente as exigências da Anvisa. Os laboratórios também precisavam alimentar os sistemas do MS e das secretarias. A pesquisa indicou que esses 
sistemas apresentavam falhas crônicas e acarretavam a necessidade da utilização de diversos controles paralelos, o que impedia a integração dos processos da cadeia de suprimentos, caso esse objetivo fosse implantado.

Mesmo considerando as sérias limitações relatadas, o estudo aqui retratado evidenciou oportunidades significativas para o funcionamento dos laboratórios públicos como uma rede de suprimentos e para o uso mais intenso das TIC no alcance desse objetivo. As entrevistas mostraram que o MS desempenhava um papel central na cadeia de suprimentos dos laboratórios farmacêuticos, podendo valer-se dessa posição para melhorar a sincronização das decisões com vistas às necessidades do SUS. Também se constatou que diversos laboratórios produziam medicamentos de uma mesma classe terapêutica, sem nenhuma avaliação mais criteriosa da complementariedade de capacidades e competências.

Esse cenário permite supor que uma atuação coordenada dos MS, das secretarias dos estados e municípios e dos laboratórios públicos poderia trazer ganhos expressivos na alocação dos escassos recursos físicos e financeiros de que o país dispõe. Por exemplo, como os laboratórios públicos visavam atender principalmente as necessidades da sociedade, talvez fosse vantajoso para o país que a produção de cada classe terapêutica fosse centralizada por um ou dois laboratórios, de acordo com as especificidades do seu parque fabril ou da sua capacidade tecnológica. Dessa maneira, seria possível especializar o laboratório na produção de determinado tipo de medicamento e, consequentemente, aumentar a produtividade, diminuir o risco de contaminação química e biológica, diminuir o custo produtivo.

Também poderia haver a transferência de pesquisadores e especialistas entre os laboratórios, caso necessário. Por fim, as parcerias com laboratórios privados e com laboratórios públicos de outros países poderiam ser utilizadas como mecanismo de aprendizagem e acúmulo de capacidade tecnológica de produção e, mais à frente, de geração de novas drogas, particularmente de biofármacos, rota tecnológica ainda em consolidação na indústria farmacêutica global.

Para reverter o quadro de múltiplos inputs e buscar uma lógica de redes de suprimentos, o MS, a Anvisa, juntamente com os laboratórios públicos e as secretarias estaduais e municipais, poderiam considerar a criação de um sistema informatizado unificado que atendesse a legislação vigente (RDC no 17) sobre as Boas Práticas de Fabricação (BPF) de medicamentos, e que atendesse ao mesmo tempo as necessidades do conjunto dos atores da rede de suprimentos dos laboratórios públicos brasileiros. Para o desenvolvimento desse SI poder-se-iam considerar inclusive as alternativas da computação em nuvem e da utilização de softwares como serviços (SaaS), tendências que parecem se consolidar na indústria de TIC.

Entretanto, as entrevistas deixaram claro que as equipes de TI dos laboratórios públicos podem ter dificuldades para acompanhar a dinâmica da evolução da TIC. Entre outras dificuldades, pode-se citar a alta rotatividade, em face dos baixos salários, de funcionários das áreas de TI e de logística, e as dificuldades para a contratação de fornecedores com vínculos mais estáveis, que façam investimentos específicos para a RBPPM, dada a legislação vigente à época desta pesquisa. Essas restrições poderiam dificultar o ciclo de desenvolvimento de sistemas mais robustos, com maior sofisticação em seus algoritmos. 
Apesar da existência de 21 laboratórios públicos membros da Alfob, constatou-se que apenas 13 encontravam-se ativos, o que pode dificultar o atendimento da necessidade de medicamentos da população brasileira de baixa renda. Alguns dos laboratórios que não estavam produzindo pertenciam a universidades e eram utilizados apenas para aprendizado dos alunos. Caso a RBPPM estivesse funcionando como uma cadeia de suprimentos nos moldes aqui discutidos, os papéis desses importantes atores poderiam ser reavaliados. Por exemplo, os laboratórios ligados às universidades federais poderiam ficar dedicados às pesquisas básicas ou aplicadas da RBPPM. Entende-se que tal rearranjo, se conduzido de forma planejada e coordenada em nível nacional, poderia contribuir para a maximização dos recursos alocados à saúde pública.

Na medida em que a RBPPM não adotava os atributos da GCS e a utilização de ferramentas de TIC era feita ainda de forma muito limitada, a suposição deste estudo não pode ser evidenciada. Ainda assim, os autores deste artigo entendem que a pesquisa contribuiu para a teoria e a prática administrativa. Do ponto de vista da teoria, a pesquisa permitiu aprofundar a investigação acadêmica sobre as TIC utilizadas direta e indiretamente na GCS de laboratórios farmacêuticos. Já do ponto de vista da prática, esta pesquisa contribuiu para mostrar aos gestores dos laboratórios farmacêuticos públicos brasileiros o potencial da utilização de uma abordagem de GCS e da contribuição das TIC para a RBPPM. A pesquisa também trouxe contribuições para a sociedade, já que a produção de medicamentos dos laboratórios estudados é destinada a atender as necessidades das camadas sociais menos favorecidas, particularmente no que tange às doenças negligenciadas.

Este estudo apresentou algumas limitações, listadas a seguir: a) a possível falta de entendimento sobre as TIC listadas nos questionários enviados por e-mail. Pelo fato de o entrevistador não estar presente durante o preenchimento do questionário, alguns itens podem ter sido respondidos equivocadamente; ii) o tamanho limitado da amostra utilizada no estudo quantitativo, devido ao número expressivo de laboratórios pertencentes à Alfob que se encontrava inativo; iii) a impossibilidade de generalizações dos resultados das entrevistas, já que foram estudados apenas três laboratórios, totalizando seis entrevistas.

Sugere-se para estudos futuros uma análise que evidencie como as TIC são utilizadas e como elas contribuem para a GCS dos laboratórios privados. Também pode ser realizado um estudo de caso comparativo entre um laboratório público e um privado, mostrando como funcionam a GCS e como as ferramentas de TIC estão contribuindo para o desempenho das redes de suprimentos. Por fim, seria interessante estender a pesquisa qualitativa para os outros 10 laboratórios que se encontravam com a produção ativa no final de 2013. 


\section{Referências}

AHLAWAT, Sunita S.; AHLAWAT, Sucheta. Competing in the global knowledge economy: implications for business education. Journal of American Academy of Business, v. 8, n. 1, p. 101-105, 2006.

ALFOB. Associação dos Laboratórios Farmacêuticos Oficiais do Brasil. Disponível em: <www.alfob. org >. Acesso em: 9 out. 2012.

BALOCCO, Raffaello et al. RFId adoption in the FMCG supply chain: an interpretative framework. Supply Chain Management: An International Journal, v. 16, n. 5, p. 299-315, 2011.

BANDEIRA, Renata A. de M.; MAÇADA, Antonio Carlos G. Relacionamento interorganizacional na cadeia de suprimentos: um estudo de caso na indústria da construção civil. Produção, v. 19, n. 2, p. 376-387, 2009.

BARBOSA, Danilo H.; CARETA, Catarina B.; MUSETTI, Marcel A. A tecnologia da informação na logística: estudo de caso em uma cadeia de suprimentos. In: SIMPÓSIO DE ENGENHARIA DE PRODUÇÃO, XIV, Bauru. Anais... Bauru: Unesp, 2007. p. 1-12.

BASTOS, Valéria D. Inovação farmacêutica: padrão setorial e perspectivas para o caso brasileiro. BNDES Setorial, v. 22, p. 271-296, set. 2005.

BUSS, Paulo M.; CARVALHEIRO, José da R.; CASAS, Carmem P. R. (Org). Medicamentos no Brasil: inovação e acesso. Rio de Janeiro: Editora Fiocruz. 2008.

CALIXTO, João B.; SIQUEIRA JUNIOR, Jarbas M. Desenvolvimento de medicamentos no Brasil: desafios. Gazeta Médica da Bahia, v. 78, n. 1, p. 98-106, 2008.

CARNEIRO, Teresa C. J. Integração organizacional e tecnologia da informação: um estudo de caso na indústria farmacêutica. Tese (doutorado) — Instituto Coppead de Administração, Universidade Federal do Rio de Janeiro, Rio de Janeiro, 2005.

CHIARONI, Davide; CHIESA, Vittorio; FRATTINI, Federico. Patterns of collaboration along the bio-pharmaceutical innovation process. Journal of Business Chemistry, v. 5, n. 1, p. 7-22, 2008.

CORRÊA, Henrique L.; GIANESI, Irineu G. N.; CAON, Mauro. Planejamento, programação e controle da produção: MRP II/ERP: conceitos, uso e implantação: base para SAP, Oracle Applications e outros softwares integrados de gestão. 5. ed. São Paulo: Atlas, 2008.

CSCMP. Council of Supply Chain Management Professionals. Supply chain and logistics terms and glossary. 2013. Disponível em: <http://cscmp.org/sites/default/files/user_uploads/resources/ downloads/glossary-2013.pdf>. Acesso em: 14 dez. 2013.

DEKKER, Rommert; BLOEMHOF, Jacqueline; MALLIDIS, Ioannis. Operations research for green logistics - an overview of aspects, issues, contributions and challenges. European Journal of Operational Research, v. 219, n. 3, p. 671-679, 2012. 
DYER, Jeffrey H.; SINGH, Harbir. The relational view: cooperative strategy and sources of interorganizational competitive advantage. Academy of Management Review, v. 23, n. 4, p. 660-679, 1998.

FELDENS, Luis F. Impacto da tecnologia da informação nas variáveis estratégicas organizacionais na gestão da cadeia de suprimentos. Dissertação (mestrado) — Escola de Administração, Universidade Federal do Rio Grande do Sul, Porto Alegre, 2005.

FRANÇOSO, Mariane S.; STRACHMAN, Eduardo. A indústria farmacêutica no Brasil e na Índia: um estudo comparativo. Revista de Economia, v. 39, n. 1, p. 91-112, 2013.

GADELHA, Carlos A. G.; QUENTAL, Cristiane; FIALHO, Beatriz C. Saúde e inovação: uma abordagem sistêmica das indústrias da saúde. Caderno de Saúde Pública, Rio de Janeiro, v. 19, n. 1, p. 47-59, jan./fev. 2003.

GIMÉNEZ, Cristina; LOURENÇO, Helena R. e-GCS: internet's impact on supply chain processes. International Journal of Logistics Management, v. 19, n. 3, p. 309-343, 2008.

GUNASEKARAN, Angappa; NGAI, Eric W. T.; McGAUGHEY, Ronald E. Information technology and systems justification: a review for research and applications. European Journal of Operational Research, v. 173, n. 3, p. 957-983, 2006.

HÅKANSSON, Håkan; PERSSON, Göran. Supply chain management: the logic of supply chains and networks. International Journal of Logistics Management, v. 1, n. 15, p. 11-26, 2004.

HVOLBY, Hans H.; WONG, Chee Y. The ERP supply chains. International Journal of Integrated Supply Management, v. 3, n. 4, p. 321-326, 2007.

JONSSON, Patrik; KJELLSDOTTER, Linea; RUDBERG, Martin. Applying advanced planning systems for supply chain planning: three case studies. International Journal of Physical Distribution \& Logistics Management, v. 37, n. 10, p. 816-834, 2007.

KUMAR, Kuldeep. Sustainable collaboration: managing conflicts and cooperation in interorganizational systems. MIS Quarterly, v. 20, n. 3, p. 279-300, 1996.

KURIEN, Georgy P.; QURESHI, Muhammad N. Study of performance measurement practices in supply chain management. International Journal of Business, Management and Social Sciences, v. 2, n. 4, p. 19-34, 2011.

LACHMAN, Leon; LIEBERMAN, Herbert A.; KANIG, Joseph L. Teoria e prática na indústria farmacêutica. 2. ed. Lisboa: Fundação Calouste Gulbenkian, 2010. v. 2.

LAMBERT, Douglas M. Customer relationship management as a business process. Journal of Business \& Industrial Marketing, v. 25, n. 1, p. 4-17, 2010.

LEE, Sang-Heui et al. A comparative study of proprietary ERP and open source ERP modules on the value chain. International Journal of Information and Decision Sciences, v. 3, n. 1, p. 26-38, 2011.

MAÇADA, Antonio C. G.; FELDENS, Luis P.; SANTOS, Andre M. Impacto da tecnologia da informação na gestão das cadeias de suprimentos: um estudo de casos múltiplos. Gestão \& Produção, v. 14, n. 1, p. 1-12, 2007. 
MAGALHÃES, Jorge L. Estratégia governamental para internalização de fármacos \& medicamentos em doenças negligenciadas. Tese (doutorado) - Universidade Federal do Rio de Janeiro, Rio de Janeiro, 2010.

MAGALHÃES, Jorge L.; ANTUNES, Adelaide M. S.; BOECHAT, Núbia A. Laboratórios farmacêuticos oficiais e sua relevância para saúde pública do Brasil. RECIIS - Revista Eletrônica de Comunicação, Informação \& Inovação em Saúde, v. 5, n. 1, p. 85-99, 2011.

MALERBA, Franco; ORSENIGNO, Luigi. Innovation and market structure in the dynamics of the pharmaceutical industry and biotechnology: towards a history friendly model. Industrial and Corporate Change, v. 11, n. 4, p. 667-703, 2002.

MARADEI JUNIOR, Fernando. Análise da cadeia de suprimentos do setor farmacêutico brasileiro quanto ao nível de colaboração entre laboratórios e operadores logísticos. Dissertação (mestrado) Escola de Administração de Empresas de São Paulo, Fundação Getulio Vargas, São Paulo, 2008.

MARQUEZ, Adolfo C. Dynamic modelling for supply chain management: dealing with front-end, back-end and integration issues. Londres: Springer, 2010.

McCARTY, John A.; HASTAK, Manoj. Segmentation approaches in data-mining: a comparison of RFM, Chaid, and logistic regression. Journal of Business Research, v. 60, n. 6, p. 656-662, 2007.

MCIVOR, Ronan; HUMPHREYS, Paul. The implications of electronic B2B intermediaries for the buyer-supplier interface. International Journal of Operations \& Production Management, v. 24, n. 3, p. 241-269, 2004.

MESQUITA, Marco A.; SANTORO, Miguel C. Análise de modelos e práticas de planejamento e controle na indústria farmacêutica. Revista Produção, v. 14, n. 1, p. 64-77, 2004.

MOHSEN, Attaran. RFID: an enabler of supply chain operations. Supply Chain Management: An International Journal, v. 12, n. 4, p. 249-257, 2007.

MOINI, Nadereh et al. Estimating the determinant factors of container dwell times at seaports. Maritime Economics \& Logistics, v. 14, n. 3, p. 162-177, 2012.

MOREIRA, Carlos A. G.; PITASSI, Claudio. Proposta de métrica do nível de capacidade tecnológica das empresas farmacêuticas brasileiras. Revista de Administração e Inovação, v. 10, n. 4, p. 229-252, 2013.

OLIVEIRA, Egléubia A.; LABRA, Maria E.; BERMUDEZ, Jorge. A produção pública de medicamentos no Brasil: uma visão geral. Cadernos de Saúde Pública, v. 22, n. 11, p. 2379-2389, 2006.

PALMEIRA FILHO, Pedro L.; PAN, Simon S. K. Cadeia farmacêutica no Brasil: avaliação preliminar e perspectivas. BNDES Setorial, v. 18, p. 3-22, out. 2003.

PIRES, Silvio R.I. Gestão da cadeia de suprimentos: conceitos, estratégias, práticas e casos — Supply Chain Management. 2. ed. São Paulo: Atlas, 2010.

PITASSI, Claudio; MORENO, Valter A. O papel das disciplinas de sistemas de informação nos cursos de graduação em administração. Revista Angrad, v. 10, n. 2, p. 9-32, 2009. 
PITASSI, Claudio; MORENO, Valter A.; GONÇALVES, Antônio A. Fatores que influenciam a adoção de ferramentas TICs nos experimentos de bioinformática de organizações biofarmacêuticas: um estudo de caso no Instituto Nacional do Câncer. Revista Ciência e Saúde Coletiva, v. 9, n. 1, p. 257-268, 2014.

RANKY, Paul G. An introduction to radio frequency identification (RFID) methods and solutions. Assembly Automation, v. 16, n. 1, p. 28-33, 2006.

RAO, G. Vidyasagar. Impact of IT in supply chain management. Journal of Business Management \& Social Sciences Research, v. 2, n. 4, p. 108-112, 2013.

RIBEIRO, Maria T. F. Gestão dos centros de P\&D face à competitividade. In: SIMPÓSIO DE GESTÃO DA INOVAÇÃO TECNOLÓGICA, XXI, São Paulo, Anais... São Paulo: Anpad, 2000.

RUDBERG, Martin; KLINGENBERG, Niklas; KRONHAMN, Kristoffer. Collaborative supply chains planning using electronic marketplaces. Integrated Manufacturing Systems, v. 13, n. 8, p. 596-610, 2002.

RYSSEL, Ricky; RITTER, Thomas; GEMÜNDEN, Hans G. The impact of information technology deployment on trust, commitment and value creation in business relationships. Journal of Business \& Industrial Marketing, v. 19, n. 3, p. 197-207, 2004.

SALO, Jari; KARJALUOTO, Heikki. IT-enabled Supply Chain Management. Contemporary Management Research, v. 2, n. 1, p. 17-30, 2006.

SAMPAIO, Mauro; CSILLAG, João M. Integração da cadeia de suprimentos da indústria farmacêutica. Revista de Administração e Inovação, v. 7, n. 1, p. 109-130, 2010.

SANCHEZ, Angel M.; PEREZ, Manuela P. EDI and cooperation in the supply chain: an empirical study in the Spanish automotive supply industry. International Journal of Automotive Technology and Management, v. 4, n. 1, p. 74-90, 2004.

SCARAMUZZO, Mônica. Sexto maior mercado global farmacêutico, Brasil carece de inovação. Valor Econômico. Disponível em <www.valor.com.br/empresas/3057208>. Acesso em: 1o mar. 2013.

SHAHABUDDIN, Syed. Supply chain management and its effect on company's performance. International Journal of Logistics Systems and Management, v. 8 n. 1, p. 101-117, 2011.

STANK, Theodore P.; GOLDSBY, Thomas J. A framework for transportation decision making in an integrated supply chain. Supply Chain Management: An International Journal, v. 5, n. 2, p. 71-78, 2000 .

STEFANSSON, Gunnar; LUMSDEN, Kenth. Performance issues of Smart Transportation Management Systems. International Journal of Productivity and Performance Management, v. 58, n. 1, p. 55-70, 2009.

TURBAN, Efraim et al. Tecnologia da informação para gestão: transformando os negócios na economia digital. 6. ed. Porto Alegre: Bookman, 2010.

VERGARA, Sylvia C. Projetos e relatórios de pesquisa em administração. 6. ed. São Paulo: Atlas, 2005. 
VIANA, Fernando L. E.; QUEIROZ, Berenice B.; LIMA, Caroline L. M. Gestão da cadeia de suprimento e vantagem competitiva relacional: uma análise na indústria de alimentos. In: ENCONTRO DA ANPAD, XXXVII, Rio de Janeiro. Anais... Rio de Janeiro: Anpad, 2013.

ZHANG, Xuan; VAN DONK, Dirk P.; VAN DER VAART, Taco. Does ICT influence supply chain management and performance? A review of survey-based research. International Journal of Operations \& Production Management, v. 31, n. 11, p. 215-247, 2011.

ZENG, Amy Z.; PATHAK, Bhavit K. Achieving information integration in supply chain management through B2B e-hubs: concepts and analyses. Industrial Management \& Data Systems, v. 103, n. 9, p. 657-665, 2003.

WEILL, Peter. Place to space: migrating to ebusiness models. Massachusetts: Harvard Business Press, 2013.

WILLIAM, J. Christensen; GERMAIN, Richard N.; BIROU, Laura. Variance $v s$ average: supply chain lead-time as a predictor of financial performance. Supply Chain Management: An International Journal, v. 12, n. 5, p. 349-357, 2007.

Ana Luíza Pimenta de Souza é analista de Gestão em Saúde da Fundação Oswaldo Cruz (Fiocruz). E-mail: apimenta@far.fiocruz.br.

Claudio Pitassi é professor assistente e pesquisador do Mestrado em Administração das Faculdades Ibmec-Rio. E-mail: claudio.pitassi@gmail.com.

Marco Aurélio Carino Bouzada é professor titular do Programa de Mestrado em Administração (Made) da Universidade Estácio de Sá (Unesa). E-mail: marco.bouzada@estacio.br.

Antônio Augusto Gonçalves é professor adjunto do Programa de Mestrado em Administração (Made) da Universidade Estácio de Sá (Unesa).E-mail: augusto@inca.gov.br. 